\title{
Analisis Kinerja Subscriber Station WiMAX di Urban Area Bandung
}

\author{
DWI ARYANTA \\ Teknik Elektro Institut Teknologi Nasional \\ dwiaryanta@gmail.com
}

\begin{abstract}
ABSTRAK
Teknologi komunikasi wireless semakin pesat mengalami perkembangan. WiMAX merupakan suatu teknologi broadband yang didukung oleh standar IEEE 802.16d (802.16-2004) yang mampu memberikan layanan data berkecepatan tinggi hingga 75 Mbps dalam radius maksimal 40-50 km pada bandwidth $20 \mathrm{MHz}$. Alokasi frekuensi yang dipakai Indonesia untuk jaringan WiMAX ini ialah 3,3-3,4 GHz. Penelitian ini dilakukan dengan melakukan proses pengukuran kinerja perangkat radio WiMAX yaitu HiMax 331-SS. Proses pengukuran dilakukan antara CPE dan base station dengan antenna sektoral $120^{\circ}$ pada ketinggian $45 \mathrm{~m}$. Lokasi pengukuran dilakukan di beberapa area kota Bandung yang telah ditentukan sebelumnya. Hasil pengukuran memperlihatkan nilai CINR tertinggi adalah 31 dB dengan modulasi 64 QAM - 3/4 dan terendah nilai $10 \mathrm{~dB}$ dengan modulasi BPSK 1/2. Nilai RSSI tertinggi $-54 \mathrm{dBm}$ berada dan nilai RSSI terendah -89 dBm. Nilai throughput tertinggi untuk layanan streaming video sebesar 1000,8 kbps (downlink) dengan modulasi 64 QAM - 3/4. Nilai delay terendah sebesar 56,247 ms pada kondisi LOS dan tertinggi sebesar 139,5 ms pada kondisi NLOS. Nilai terbesar packet loss sebesar $20 \%$ yaitu pada lokasi pengukuran terjauh $14,3 \mathrm{~km}$.
\end{abstract}

Kata Kunci : delay, packet loss, RSSI, CINR, throughput, CPE, WiMAX.

\begin{abstract}
Wireless communication technologies have evolved more rapidly. WiMAX is a broadband technology that is supported by the IEEE standard 802.16-2004/d which is able to provide high speed data services of up to 75 Mbps within a radius of $40-50 \mathrm{~km}$ at a maximum bandwidth of $20 \mathrm{MHz}$. Indonesia frequency allocation used for the WiMAX network is 3.3 to $3.4 \mathrm{GHz}$. This study was conducted with the performance measurement process that is Himax 331 WiMAX radio - SS. Process measurement is made between the CPE and base station sector antennas at a height of $45 \mathrm{~m}$ in 1200. Locations measurements performed in several areas of Bandung predetermined. The measurement results show the highest CINR value is $31 d B$ with 64 QAM modulation - 3/4 and the lowest value of $10 \mathrm{~dB}$ with BPSK modulation half. The highest RSSI value of $-54 \mathrm{dBm}$ being the lowest and $-89 \mathrm{dBm}$ RSSI value. The highest throughput for streaming video services by $1000.8 \mathrm{kbps}$ (downlink) with 64 QAM modulation - 3/4. The lowest value was 56.247 ms delay in LOS conditions and the highest was $139.5 \mathrm{~ms}$ in NLOS conditions. The greatest value by $20 \%$ packet loss is the farthest measurement locations $14.3 \mathrm{~km}$.
\end{abstract}

Keywords : delay, packet loss, RSSI, CINR, throughput, CPE, WiMAX. 


\section{PENDAHULUAN}

Pesatnya perkembangan layanan informasi komunikasi membuat informasi semakin mudah didapat. Layanan informasi yang pada awalnya hanya berupa suara melalui perantara kabel atau yang dikenal dengan PSTN, sekarang telah berkembang pesat untuk dapat memenuhi kebutuhan informasi berupa suara, video, dan data secara bersamaan. Pada layanan informasi data (multimedia) dan video, kecepatan dan kestabilan dalam pengiriman data maupun video merupakan parameter penting bagi pengguna. Seperti layaknya komunikasi video yang membutuhkan bandwidth yang besar karena melibatkan transmisi suara dan data secara real time. Sehingga diperlukan teknologi yang dapat mentransmisikan data, suara, maupun video dengan kecepatan yang tinggi dan tetap stabil. Teknologi yang digunakan dulu masih berupa tradisional broadband yang dilewatkan melalui saluran telepon dan kabel yang perkembangannya lambat karena masalah pemasangan, pengembangan, dan pembangunan infrastruktur yang mahal dan terbatas.

Hadirnya teknologi dengan standar IEEE 802.16d menjadikan koneksi nirkabel kecepatan tinggi dengan biaya yang efektif ke pengguna rumahan dan bisnis, baik yang berada di perkotaan maupun daerah. IEEE 802.16d merupakan standar teknologi wireless pita lebar yang disediakan untuk pelanggan yang tidak bergerak atau fixed wireless akses dan pelanggan bergerak dengan mobilitas yang terbatas atau limited mobility. Menggunakan frekuensi yang cukup tinggi (2-11 $\mathrm{GHz}$ ) serta bandwidth kanal yang cukup lebar dan dapat diatur sesuai kebutuhan, dimana WiMAX mampu memberikan data rate dan throughput yang tinggi (Milanovic, 2007). Teknologi ini dapat mendukung berbagai bentuk layanan data berbasiskan paket, multimedia, dan internet seperti : transfer data kecepatan tinggi, video streaming, VoIP telephony, tayangan diam maupun gerak, e-mail, Web browsing, dan e-commerce.

WiMAX merupakan nama industri untuk kelompok standar IEEE 802.16 dan dipromosikan oleh organisasi non-profit WiMAX Forum. IEEE 802.16 merupakan teknologi yang membahas air interface untuk broadband wireless access system pada wilayah metropolitan area network (MAN). WiMAX dan WiFi (Wireless Fidelity) dibedakan berdasarkan standar teknik yang bergabung di dalamnya. WiFi menggabungkan IEEE 802.11 dengan ETSI (European Telecommunications Standards Institute) HiperLAN (Hiper Local Area Network) yang merupakan standar teknis yang cocok untuk keperluan WLAN. Sedangkan WiMAX merupakan penggabungan antara standar IEEE 802.16 dengan ETSI HiperMAN (Hiper Metropolitan Area Network).

Terdapat sejumlah varian IEEE 802.16 yang dimaksudkan untuk mengembangkan kinerja dan kemampuan dari teknologi yang digunakannya, agar menjadi lebih handal dan dapat meluas penggunaannya. Untuk mengembangkan jangkauan dan daya jualnya, maka standar IEEE 802.16 direvisi menjadi IEEE 802.16a. Standar teknis IEEE 802.16a inilah yang banyak digunakan oleh perangkat-perangkat dengan sertifikasi WiMAX. Perubahan yang cukup signifikan pada standar IEEE 802.16 untuk membentuk varian IEEE 802.16a, adalah lebar frekuensi operasinya. Perbedaan ini dimaksudkan untuk mendukung komunikasi dalam kondisi line of sight (LOS), dan non line of sight (NLOS) (Shabbir, 2011). Dengan adanya sistem 
NLOS, keterbatasan yang ada pada WiFi dapat dikurangi. Tabel 1 menguraikan sejumlah perbedaan spesifikasi teknis dari varian standar IEEE 802.16 (Shahajahan, 2009).

Tabel 1. Varian-varian standar I EEE 802.16.

\begin{tabular}{|c|c|c|c|}
\hline & 802.16 & 802.16alRev d & $802.16 e$ \\
\hline Completed & December 2001 & $\begin{array}{l}\text { 802.16a: Jan } 2003 \\
802.16 \text { Revd: June } 2004\end{array}$ & Est. Mid-2005 \\
\hline Spectrum & $10-66 \mathrm{GHz}$ & $2-11 \mathrm{GHz}$ & $2-6 \mathrm{GHz}$ \\
\hline Application & Backhaul & Wireless DSL \& Backhaul & Mobile Intemet \\
\hline $\begin{array}{l}\text { Channel } \\
\text { Conditions }\end{array}$ & Line of Sight Only & Non Line of Sight & Non Line of Sight \\
\hline Bit Rate & $\begin{array}{l}32-134 \mathrm{Mbps} \text { at } 28 \mathrm{MHz} \\
\text { channelization }\end{array}$ & $\begin{array}{l}\text { Up to } 75 \mathrm{Mbps} \text { at } 20 \mathrm{MHz} \\
\text { channelization }\end{array}$ & $\begin{array}{l}\text { Up to } 15 \mathrm{Mbps} \text { at } 5 \mathrm{MHz} \\
\text { channelization }\end{array}$ \\
\hline Modulation & $\begin{array}{l}\text { QPSK, 16QAM and } \\
\text { 64QAM }\end{array}$ & $\begin{array}{l}\text { OFDM } 256 \text { sub-carriers } \\
\text { QPSK, 16QAM, 64QAM }\end{array}$ & Scalable OFDMA \\
\hline Mobility & Fixed & Fixed & $\begin{array}{l}\text { Pedestrian Mobility - } \\
\text { Regional Roarning }\end{array}$ \\
\hline $\begin{array}{l}\text { Channel } \\
\text { Bandwidths }\end{array}$ & 20,25 and $28 \mathrm{MHz}$ & $\begin{array}{l}\text { Selectable channel } \\
\text { bandwidths between } 1.5 \text { and } \\
20 \mathrm{MHz}\end{array}$ & $\begin{array}{l}\text { Same as } 802.16 \text { a with UL } \\
\text { sub-channels to conserve } \\
\text { power }\end{array}$ \\
\hline $\begin{array}{l}\text { Typical Cell } \\
\text { Radius }\end{array}$ & 1-3 miles & $\begin{array}{l}4 \text { to } 6 \text { miles; Max range } 30 \\
\text { miles based on tower height, } \\
\text { antenna gain and power } \\
\text { transmit }\end{array}$ & $1-3$ miles \\
\hline
\end{tabular}

Pada sistem komunikasi wireless telah umum dikenal kondisi LOS dan NLOS. Hal ini berkaitan dengan daerah pancar antara BS (Base Station) dan SS (Subscriber Station) yang lebih dikenal dengan Fressnel Zone clearence. Pada kondisi LOS, antara pengirim dan penerima saling lihat secara langsung tanpa ada rintangan (first Fressnel zone). Apabila kriteria ini tidak terpenuhi, maka penerimaan sinyal akan menurun secara drastis. Kemampuan NLOS pada WiMAX ditunjang oleh penerapan beberapa inovasi teknologi antara lain:

- modulasi adaptif (adaptive modulation) dan teknik error correction

- teknologi OFDM dan sub-kanalisasi (Sub-Channelization)

- antena direksional (directional antenna)

- diversitas pada transmitter dan receiver

- $\quad$ pengendalian daya (power contro)

Modulasi adaptif adalah skema transmisi pada komunikasi digital dimana transmitter mengadaptasi mode transmisi dengan kondisi kanal. Secara efektif dapat mengatur keseimbangan kebutuhan bandwidth dan kualitas link. Apabila kualitas sinyal cukup baik, maka digunakan modulasi yang lebih tinggi untuk memberikan kapasitas bandwidth yang lebih besar. Apabila kualitas link menurun, sistem modulasinya bergeser ke derajat yang lebih rendah untuk menjaga kestabilan dan kualitas sambungan (Milanovic, 2007).

OFDM merupakan teknologi yang terbukti dapat digunakan untuk mengatasi berbagai macam 
permasalahan propagasi (multipath), termasuk kondisi NLOS antara BS dan SS. Dapat juga mengatasi permasalah delay spread dan Inter Symbol Interference (ISI). Sinyal OFDM dibentuk oleh beberapa sinyal sempit yang dipancarkan secara pararel untuk setiap informasi yang dikirim (Ghosh, 2005).

Tantangan utama pada performansi jaringan wireless adalah penyediaan jaminan QoS (Quality of Services) dan dukungan arsitektur yang memberikan dukungan QA (Quality Asscurace) bagi sistem wireless seperti QA pada sistem wireline. Namun aspek lain performansi secara umum meliputi:

- Kinerja hardware yang meliputi parameter yang berhubungan dengan performansi minimum yang dibutuhkan perangkat transmitter dan receiver (noise figure, $\mathrm{C} / \mathrm{N}$, dan $\mathrm{BER}$ ) untuk menghasilkan kinerja sistem dalam rentang frekuensi tertentu.

- Kinerja radio yang berhubungan dengan kemampuan layer fisik dalam menangani berbagai kondisi kanal, dengan kata lain performansi yang berhubungan dengan kondisi lingkungan propagasi.

- Kinerja layer network yang berhubungan dengan penyediaan jaminan QoS untuk berbagai jenis layanan, dengan kata lain penyediaan dukungan bagi MAC (medium access control) untuk berbagai turunan layanan.

\section{METODOLOGI PENELITIAN}

\subsection{Konfigurasi Pengujian WiMAX}

Konfigurasi sistem yang digunakan untuk pengujian link pada perangkat WiMAX menggunakan HiMax 331-SS mengacu pada tingkatan pengujian berikut ini:

1. Conformance Test, melakukan penyesuaian antara spesifikasi teknis perangkat dengan kondisi di lapangan.

2. Performance Test, pengujian kualitas penerimaan sinyal pada jarak-jarak tertentu, meliputi throughput, stabilitas sistem, dan cakupan area yang mampu dilayani.

3. Function Test, uji coba yang dilakukan meliputi fungsi SS dan koneksi ke intranet/internet.

Parameter-parameter yang akan diukur meliputi : RSSI, CINR, delay, troughput, packet loss, daya pancar dan sistem Modulasi. Secara umum, elemen jaringan yang terdapat pada konfigurasi uji coba tersebut terdiri dari :

- I nternet backbone

Internet merupakan sekumpulan jaringan yang tersebar di seluruh dunia yang saling terhubung satu sama lain sehingga akan membentuk suatu jaringan komputer yang lebih besar. Backbone yang diuji menggunakan backbone dari suatu operator seluler GSM.

- NMS (Network Management System)

Protokol manajemen yang digunakan berbasiskan protokol SNMP (Simple Network Management Protocol). 
- BS (Base Station)

Base Station merupakan perangkat transceiver yang terhubung dengan internet backbone. Antena yang digunakan adalah Himax 331-ANT120 berdimensi $(24,8 \times 6,3 \times$ 2,3) $\mathrm{cm}$ dan berat 2,3 kg, memilki penguatan $15-18 \mathrm{~dB}$, frekuensi $3,3-3,4 \mathrm{GHz}$, Horizontal Beam Width $120^{\circ}$, dan Vertical Beam Width $8^{0}$.

- SS (Subscriber Station), meliputi :

1. CPE (Customer Premises Equipment)

CPE merupakan perangkat pada sisi pelanggan yang berfungsi untuk melakukan proses decoding serta demodulasi pada data-data yang diterima dari Base Station, sehingga menjadi suatu informasi yang dapat dibaca oleh pelanggan. CPE dilengkapi dengan software built in Himax 331 SS yang dapat dioperasikan dan menampilkan parameter SNR, RSSI, dan jenis modulasi.

2. PoE Injector/Splitter

CPE mendapat tegangan DC dari PoE melalui kabel RJ-45. Data dan tegangan secara bersamaan dilalui pada 1 kabel RJ 45.

\subsection{Kondisi Area Ujicoba}

Ujicoba WiMAX dilakukan di beberapa lokasi di kota Bandung, dimana terdapat 7 titik, seperti yang ditunjukan pada Gambar 1, yang dijadikan sebagai titik pengujian. Lokasi uji coba merupakan tempat yang memudahkan untuk pengukuran dengan karakter lingkungan yang bervariasi.

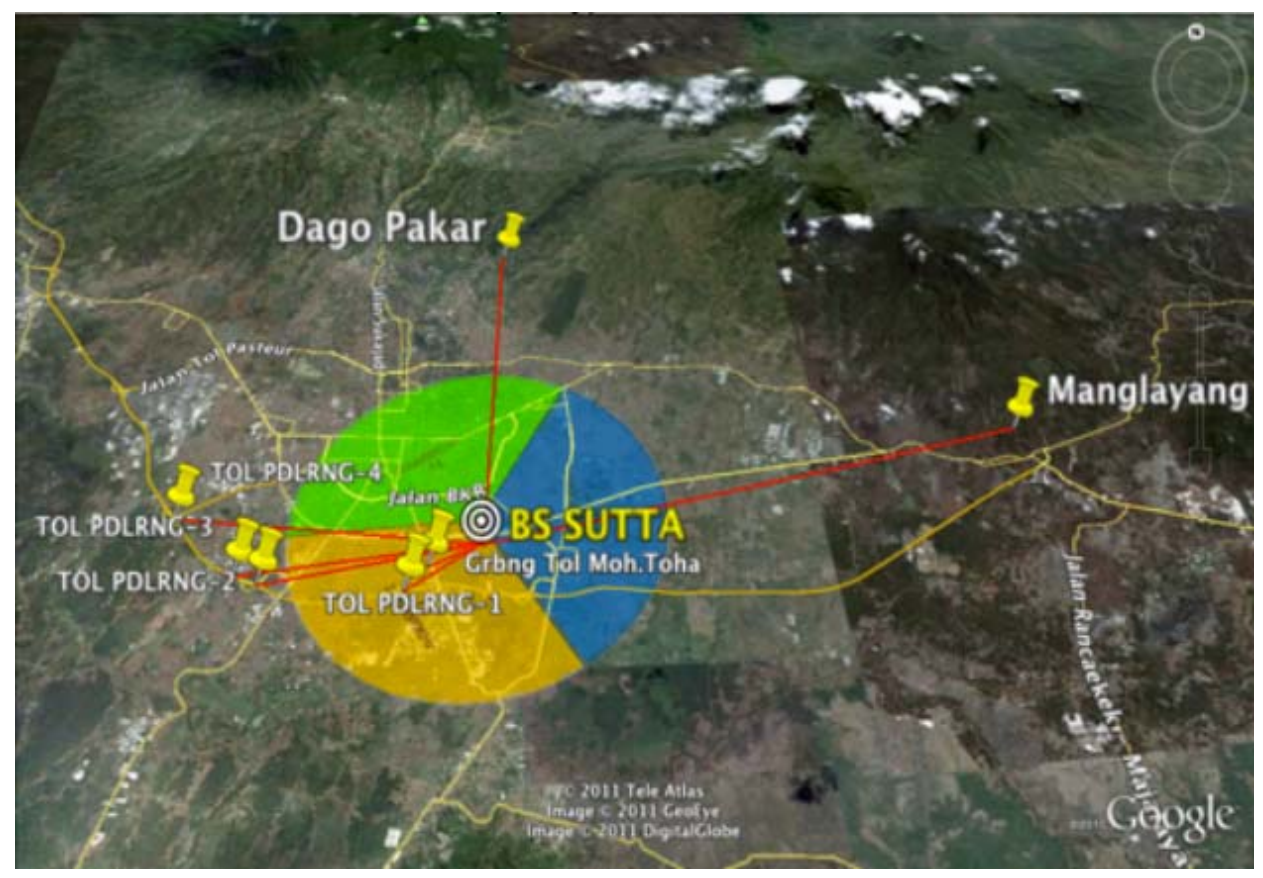

Gambar 1. Tujuh Lokasi Pengujian WiMAX di Bandung 
Koordinat untuk ke-7 lokasi di atas dapat dilihat pada Tabel 2, nilai koordinat ini diperoleh dengan pengukuran menggunakan GPS. Dari koordinat tersebut dapat ditentukan jarak udara antara base station ke titik pengukuran.

Tabel 2. Posisi koordinat dan Jarak BS - SS

\begin{tabular}{|c|l|c|c|c|}
\hline No & $\begin{array}{c}\text { Lokasi Titik } \\
\text { Pengujian }\end{array}$ & Lintang & Bujur & $\begin{array}{c}\text { Jarak BS-SS } \\
\text { (Km) }\end{array}$ \\
\hline 1 & Gerbang Tol M. Toha & $6^{\circ} 57^{\prime} 22,92^{\prime \prime} \mathrm{S}$ & $107^{\circ} 36^{\prime} 39,90^{\prime \prime} \mathrm{E}$ & 1,42 \\
\hline 2 & Tol Padalarang-1 & $6^{\circ} 57^{\prime} 42,60^{\prime \prime} \mathrm{S}$ & $107^{\circ} 36^{\prime} 21,84^{\prime \prime} \mathrm{E}$ & 2,2 \\
\hline 3 & Tol Padalarang-2 & $6^{\circ} 57^{\prime} 27,00^{\prime \prime} \mathrm{S}$ & $107^{\circ} 34^{\prime} 27,12^{\prime \prime} \mathrm{E}$ & 5,42 \\
\hline 4 & Tol Padalarang-3 & $6^{\circ} 57^{\prime} 17,28^{\prime \prime} \mathrm{S}$ & $107^{\circ} 34^{\prime} 8,10^{\prime \prime} \mathrm{E}$ & 5,97 \\
\hline 5 & Tol Padalarang-4 & $6^{\circ} 56^{\prime} 21,30^{\prime \prime} \mathrm{S}$ & $107^{\circ} 33^{\prime} 12,6^{\prime \prime} \mathrm{E}$ & 7,77 \\
\hline 6 & Dago Pakar & $6^{\circ} 51^{\prime} 48,20^{\prime \prime} \mathrm{S}$ & $107^{\circ} 37^{\prime} 43,80^{\prime \prime} \mathrm{E}$ & 9,73 \\
\hline 7 & Manglayang & $6^{\circ} 55^{\prime} 55,50^{\prime \prime} \mathrm{S}$ & $107^{\circ} 45^{\prime} 3,40^{\prime \prime} \mathrm{E}$ & 14,29 \\
\hline
\end{tabular}

\subsection{Metode Pengukuran}

Pada uji coba perangkat WiMAX ini, base station berlokasi di Jl. Soekarno Hatta Bandung, sedangkan CPE terdapat pada area outdoor di 7 tempat. CPE disini hanya bersifat fixed node dan pengukuran dilakukan menggunakan notebook yang dihubungkan dengan perangkat CPE. Beberapa informasi yang ditampilkan oleh sistem saat setelah hubungan BS dan SS berhasil dilakukan meliputi frekuensi yang digunakan, lebarnya bandwidth, CNIR, RSSI, dan beberapa parameter lainnya seperti yang ditampilkan pada Gambar 2.

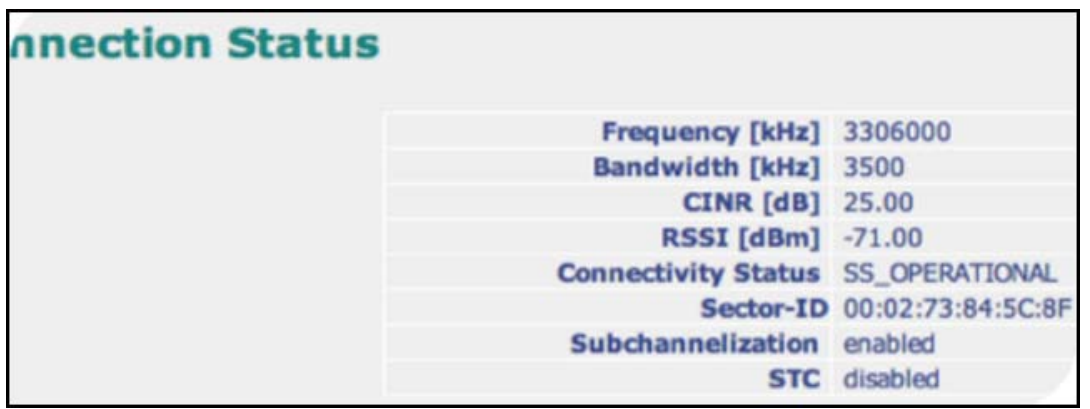

Gambar 2. Parameter Radio Pada Status Sistem

Untuk pengaturan lebih lanjut, khususnya penggunaan kanal, terdapat pilihan pada menu scanner channel, dimana kita dapat melihat dan menentukan alokasi frekuensi mana yang disediakan oleh base station agar CPE dapat terkoneksi. Informasi lain yang lebih lengkap mengenai sistem antara lain seperti jenis modulasi yang digunakan, dan semua parameter radio pada arah uplink dan downlink ditunjukan pada Gambar 3. 


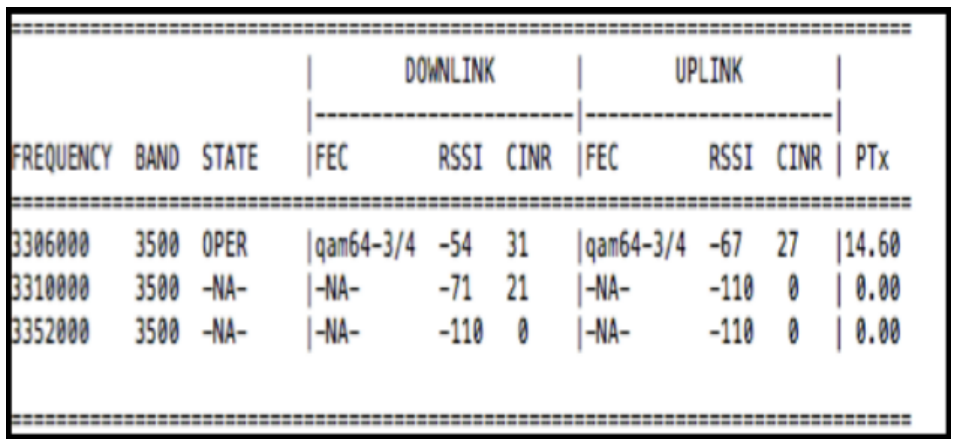

\section{Gambar 3. Parameter Radio Sistem}

Untuk dapat melihat parameter komunikasi data seperti delay dan packet loss dapat dipergunakan dengan perintah "ping" pada command windows, dimana dilakukan pengiriman paket tiap CPE memiliki 10 paket yang masing-masing berukuran 64 byte. Troughput dari koneksi diukur menggunakan aplikasi tambahan yaitu Net Monitor.

Alokasi frekuensi kerja yang digunakan perangkat dalam pengukuran WiMAX ini menggunakan 3,3 GHz. Frekuensi yang digunakan pada pengukuran ini merupakan frekuensi dimana alat ini mendapat perizinan dari wilayah pemerintah daerah setempat. Sedangkan apabila mengacu pada tetapan IEEE yang digunakan di wilayah Asia Pasifik yaitu 3,5 GHz.

\section{HASI L DAN PEMBAHASAN}

\subsection{Hasil Pengujian di Lapangan}

RSSI/RSL (Received Signal Strength Indicator) adalah indikator kekuatan sinyal yang diterima oleh penerima. Besarnya RSSI untuk arah downlink menunjukkan berapa besar daya yang diterima di sisi subscriber system (SS) dan untuk arah uplink menunjukkan berapa besar daya yang diterima di sisi base station (BS). Nilai RSSI yang didapat harus lebih besar dari Receiver Sensitivity (RSSI $\geq$ Rx sensitivity), dimana besarnya Rx sensitivity sesuai dengan spesifikasi dari perangkat yang digunakan dalam pengukuran yaitu $-99 \mathrm{dBm}$ sampai $-81 \mathrm{dBm}$ pada bandwidth 3,5 MHz. Hasil pengukuran dari seluruh titik lokasi pengujian seperti kualitas link, troughput, delay dan packet loss ditampilkan pada Tabel 3 berikut.

Tabel 3. Hasil Pengukuran Kualitas Link

\begin{tabular}{|c|c|c|c|c|c|c|c|c|c|}
\hline \multirow[b]{2}{*}{ No } & \multirow[b]{2}{*}{$\begin{array}{l}\text { Lokasi Titik } \\
\text { Pengujian }\end{array}$} & \multirow[b]{2}{*}{$\begin{array}{c}\text { Frek } \\
(\mathrm{MHz})\end{array}$} & \multicolumn{3}{|c|}{ Downlik } & \multicolumn{3}{|c|}{ Uplink } & \multirow{2}{*}{$\underset{(\mathrm{dBm})}{\mathbf{P}_{\mathrm{Tx}}}$} \\
\hline & & & Modulasi & \begin{tabular}{|c|} 
RSSI \\
(dBm)
\end{tabular} & $\begin{array}{l}\text { CINR } \\
\text { (dB) }\end{array}$ & Modulasi & $\begin{array}{c}\text { RSSI } \\
\text { (dBm) }\end{array}$ & $\begin{array}{l}\text { CINR } \\
\text { (dB) }\end{array}$ & \\
\hline 1 & Gerbang Tol M. Toha & 3306 & 64QAM-3/4 & -71 & 26 & 64QAM-3/4 & -74 & 23 & 23,14 \\
\hline 2 & Tol Padalarang-1 & 3306 & 64QAM-3/4 & -54 & 31 & 64QAM-3/4 & -67 & 27 & 14,6 \\
\hline 3 & Tol Padalarang-2 & 3306 & BPSK-1/2 & -89 & 10 & BPSK-1/2 & -92 & 9 & 22,85 \\
\hline 4 & Tol Padalarang-3 & 3310 & QPSK-3/4 & -83 & 16 & QPSK-1/2 & -92 & 8 & 22,8 \\
\hline 5 & Tol Padalarang-4 & 3310 & QPSK-1/2 & -87 & 12 & BPSK-1/2 & -92 & 7 & 22,8 \\
\hline 6 & Dago Pakar & 3310 & 64QAM-3/4 & -75 & 23 & 16QAM-1/2 & -80 & 19 & 22,8 \\
\hline 7 & Manglayang & 3352 & QPSK-3/4 & -81 & 15 & 16QAM-1/2 & -81 & 18 & 22,58 \\
\hline
\end{tabular}


Nilai RSSI tertinggi didapat $-54 \mathrm{dBm}$ berada di lokasi No.2 dan nilai RSSI terendah didapat -89 $\mathrm{dBm}$ pada lokasi No.3. Nilai CINR terbesar didapat pada lokasi No.2 yaitu sebesar $31 \mathrm{~dB}$ dengan modulasi 64 QAM 3/4. Sedangkan nilai CINR terkecil didapat dilokasi No.3 yaitu sebesar $10 \mathrm{~dB}$ dengan modulasi BPSK $1 / 2$. Terlihat pada tabel bahwa semakin besar nilai CINR maka tingkat kompleksitas modulasinya semakin bertambah.

Nilai Power Control $\left(\mathrm{P}_{\mathrm{Tx}}\right)$ terbesar ada pada lokasi gerbang tol mohammad toha yaitu 23,14 $\mathrm{dBm}$. Sedangkan yang terendah yaitu ada pada lokasi Tol Padalarang-1. Nilai $\mathrm{P}_{\mathrm{Tx}}$ ini dapat dipengaruhi oleh bebrapa faktor yaitu :

- Jarak

- Daerah pemancaran antena dan

- Jumlah CPE yang diterima oleh base station

- Nilai yang tertera masih dalam proses penstabilan

\subsection{Perhitungan Kinerja Sistem Penerimaan WiMAX}

Setelah melakukan pengujian dengan hasil yang sudah disampaikan pada bagian sebelumnya, maka langkah berikutnya adalah melakukan kajian dari sisi perhitungan berdasarkan referensi. Parameter-parameter yang digunakan untuk menganalisa performansi sistem antara lain : perhitungan link budget (perhitungan loss atau redaman propagasi, perhitungan EIRP, perhitungan RSSI), perhitungan kualitas sinyal transmisi pada parameter CINR. Parameterparameter yang mempengaruhi kondisi propagasi suatu kanal wireless meliputi lingkungan propagasi, Rugi-rugi propagasi, Fading, dan Noise.

\subsubsection{Perhitungan Loss Propagasi}

Teknologi WiMAX memungkinkan propagasi menggunakan kanal LOS dan NLOS. Pada kondisi kanal NLOS, sinyal yang ditangkap di penerima (receiver) adalah sinyal yang telah mengalami proses refleksi, scattering dan difraksi. Salah satu model propagasi yang dapat digunakan pada jaringan WiMAX X adalah model propagasi SUI (Standford University Interim) untuk kondisi NLOS yang menggunakan 3 tipe dasar terrain yaitu :

- Kategori A - Hilly/moderate-to-heavy tree density (urban)

- Kategori B - Hilly/light tree density or flat/intermediate (sub urban)

- Kategori C - Flat/light tree density (rura)

Perhitungan loss propagasi menggunakan model SUI dapat dilihat pada persamaan 1 (Shabbir, 2011):

$$
\begin{array}{ll}
L_{\text {Frop }}=A_{0}+10 n \log \left(\frac{d}{d_{0}}\right)+\Delta L_{f}+\Delta L_{h}+s \quad\left[d \delta^{\circ}\right] \\
\Delta L_{f}=6 \log \left(\frac{f}{2000}\right) & ;(\text { untuk Terrain A dan B) } \\
\Delta L_{h}=-10,0 \log \left(\frac{h}{2}\right) & ;(\text { untuk Terrain C) } \\
\Delta L_{h}=-20 \log g\left(\frac{h}{2}\right) & \\
n=a-\left(b \times h_{b}\right)+\left(\frac{g}{h_{0}}\right) &
\end{array}
$$


Dimana :

$\mathrm{A}_{0}=$ free path loss $\mathrm{d}_{0}$,

$\mathrm{d}_{0}=100 \mathrm{~m}$ jarak referensi

$\mathrm{n} \quad$ = path loss exponent

$\mathrm{d}=$ jarak jarak BS dan SS

$\Delta \mathrm{L}_{\mathrm{f}}=$ faktor koreksi frekuensi

$\Delta \mathrm{L}_{\mathrm{h}}=$ faktor koreksi tinggi antena penerima

$\mathrm{S}=$ shadow fading component $(8,2-10,6 \mathrm{~dB}$; bergantung tipe terrain)

$\mathrm{h}=$ Tinggi antena penerima $(2 \leq \mathrm{h} \leq 8 \mathrm{~m})$

$\mathrm{hb}=$ Tinggi antena SS $(10 \leq \mathrm{h} \leq 80 \mathrm{~m})$

$\mathrm{a}, \mathrm{b}$, dan $\mathrm{c}=$ konstanta yang menunjukkan kategori terrain yang ditunjukan pada Tabel 4

Tabel 4. Parameter Model Stanford University I nterism (SUI) (Shabbir, 2011)

\begin{tabular}{|c|c|c|c|}
\hline Parameter Model & Terrain Tipe A & Terrain Tipe B & Terrain Tipe C \\
\hline a & 4,6 & 4 & 3,6 \\
\hline b & 0,0075 & 0,0065 & 0,005 \\
\hline c & 12,6 & 17,1 & 20 \\
\hline S & 8,2 & 9,6 & 10,6 \\
\hline
\end{tabular}

\subsubsection{Perhitungan RSSI (Receive Signal Strength Indicator)}

RSSI adalah level sinyal yang diterima di penerima dan nilainya harus lebih besar dari sensitivitas perangkat penerima (RSSI $\geq R_{\mathrm{th}}$ ). Sensitivitas perangkat penerima merupakan kepekaan suatu perangkat pada sisi penerima yang dijadikan ukuran threshold.

Nilai RSSI dapat dihitung dengan persamaan 2 berikut (Milanovic, 2007):

$$
\text { RSSI = EIRP }-\mathbf{L}_{\text {prop }}+\mathbf{G}_{R x}-\mathbf{L}_{R x}
$$

dimana :

$\mathrm{EIRP}=$ Effective Isotropic Radiated Power $(\mathrm{dBm})$

$\mathrm{L}_{\text {prop }}=$ rugi-rugi gelombang saat berpropagasi $(\mathrm{dB})$

$\mathrm{G}_{\mathrm{Rx}}=$ penguatan antena penerima $(\mathrm{dBi})$

$L_{R x}=$ rugi-rugi saluran penerima $(d B)$

Parameter sistem komunikasi berdasarkan data teknik meliputi:

- Tx Power BS : $27 \mathrm{dBm}$

- Loss Tx (feeder + connector): $4 \mathrm{~dB}$

- Loss Rx : $2 \mathrm{~dB}$

- Gain Tx (BS) : $15 \mathrm{dBi}$

- Gain Rx : $11 \mathrm{dBi}$

- Tinggi SS : $4 \mathrm{~m}$

- Tinggi BS : $45 \mathrm{~m}$

- Shadow fading (Terrain B) : 9,6 dB 
Untuk parameter terrain dipilih dari nilai shadow fading terrain tipe B yaitu hilly/light tree density (sub urban). Hasil perhitungan menggunakan model propagasi SUI kemudian dipergunakan untuk menghitung daya terima untuk kemudian dibandingkan dengan RSSI hasil pengukuran, hasil perbandingan ditampilkan pada Tabel 5.

Tabel 5. Perbandingan RSSI Pengukuran dan Perhitungan

\begin{tabular}{|c|l|c|c|c|c|c|}
\hline \multirow{2}{*}{ No } & \multicolumn{1}{|c|}{$\begin{array}{c}\text { Lokasi Titik } \\
\text { Pengujian }\end{array}$} & $\begin{array}{c}\text { Frek } \\
(\mathbf{M H z})\end{array}$ & \multirow{2}{*}{ Modulasi } & $\begin{array}{c}\text { Jarak SS- } \\
\text { BS (Km) }\end{array}$ & \multicolumn{2}{c|}{ Daya Terima SS (dBm) } \\
\cline { 6 - 7 } & Pengukuran & Perhitungan \\
\hline 1 & Gerbang Tol M. Toha & 3306 & $64 Q A M-3 / 4$ & 1,42 & -71 & $-90,3$ \\
\hline 2 & Tol Padalarang-1 & 3306 & $64 Q A M-3 / 4$ & 2,2 & -54 & $-62,2$ \\
\hline 3 & Tol Padalarang-2 & 3306 & BPSK-1/2 & 5,42 & -89 & $-110,1$ \\
\hline 4 & Tol Padalarang-3 & 3310 & QPSK-3/4 & 5,97 & -83 & -115 \\
\hline 5 & Tol Padalarang-4 & 3310 & QPSK-1/2 & 7,77 & -87 & $-119,7$ \\
\hline 6 & Dago Pakar & 3310 & $64 Q A M-3 / 4$ & 9,73 & -75 & $-76,61$ \\
\hline 7 & Manglayang & 3352 & QPSK-3/4 & 14,29 & -81 & $-79,1$ \\
\hline
\end{tabular}

Nilai perhitungan ini dibandingkan dengan nilai RSSI yang diterima oleh pengukuran yaitu sebesar -71 dBm. Nilai yang didapat perhitungan berbeda $19 \mathrm{~dB}$ dengan pengukuran. Hal ini dapat disebabkan oleh beberapa nilai asumsi seperti redaman kabel dan penguatan antena penerima.

\subsubsection{Perhitungan CI NR (Carrier to Interference+Noise Ratio)}

CINR merupakan perbandingan antara daya sinyal dengan daya noise pada kanal. Nilai CINR dapat dihitung dengan persamaan :

CINR (dB) = RSSI (dBW) + $204-N F-10 \log R_{b}$

dimana :

$\mathrm{R}_{\mathrm{B}}=$ bit rate $(\mathrm{bps})$

$\mathrm{NF}=$ noise figure

RSSI $=$ Receive signal strength indicator $(\mathrm{dBw})$

Parameter CINR (Carrier to Interference-plus-Noise Ratio) menunjukkan kuat daya sinyal dibandingkan dengan daya noise pada kanal transmisi. Standar IEEE 802.16d yang menggunakan adaptive modulation membuat perangkat berpindah jenis modulasi terhadap nilai CINR yang diterima. Tabel 6 menampilkan batasan modulasi terhadap parameter lain. 
Tabel 6. Skema Modulasi pada 3.5 MHz

\begin{tabular}{lcccc}
\hline Modulation & 3.5 MHz sensitivity $(\mathrm{dBm})$ & SNR $(\mathrm{dB})$ & Theoretical $(\mathrm{Mbps})$ & Actual $(\mathrm{Mbps})$ \\
\hline & & & & \\
BPSK 1/2 & -90.6 & 6.4 & 1.41 & 0.86 \\
BPSK 3/4 & -88.6 & 8.5 & 2.1 & 1.28 \\
QPSK 1/2 & -87.6 & 9.4 & 2.82 & 1.72 \\
QPSK 3 $/ 4$ & -85.8 & 11.2 & 4.23 & 2.58 \\
16QAM 1/2 & -80.6 & 16.4 & 5.64 & 3.44 \\
16QAM 3/4 & -78.8 & 18.2 & 8.47 & 5.16 \\
64QAM 2/3 & -74.3 & 22.7 & 11.29 & 6.88 \\
64QAM 3/4 & -72.6 & 24.4 & 12.71 & 7.74 \\
\hline
\end{tabular}

Tabel 7 menunjukan perbandingan CINR berdasar hasil pengukuran dan perhitungan.

Tabel 7. Perbandingan CNIR Hasil Pengukuran Dengan Perhitungan

\begin{tabular}{|c|c|c|c|c|c|c|}
\hline \multirow{2}{*}{ No } & \multirow{2}{*}{$\begin{array}{c}\text { Lokasi Titik } \\
\text { Pengujian }\end{array}$} & \multirow{2}{*}{$\begin{array}{c}\text { Frek } \\
(\mathrm{MHz})\end{array}$} & \multirow{2}{*}{ Modulasi } & \multirow{2}{*}{$\begin{array}{c}\text { Jarak SS- } \\
\text { BS (Km) }\end{array}$} & \multicolumn{2}{|c|}{ CNI R SS (dBm) } \\
\hline & & & & & Pengukuran & Perhitungan \\
\hline 1 & Gerbang Tol M. Toha & 3306 & 64QAM-3/4 & 1,42 & 26 & 7,81 \\
\hline 2 & Tol Padalarang-1 & 3306 & 64QAM-3/4 & 2,2 & 31 & 35,9 \\
\hline 3 & Tol Padalarang-2 & 3306 & BPSK-1/2 & 5,42 & 10 & $-2,4$ \\
\hline 4 & Tol Padalarang-3 & 3310 & QPSK-3/4 & 5,97 & 16 & $-12,11$ \\
\hline 5 & Tol Padalarang-4 & 3310 & QPSK-1/2 & 7,77 & 12 & $-15,1$ \\
\hline 6 & Dago Pakar & 3310 & 64QAM-3/4 & 9,73 & 23 & 22,5 \\
\hline 7 & Manglayang & 3352 & QPSK-3/4 & 14,29 & 15 & 23,8 \\
\hline
\end{tabular}

Dari hasil di atas tampak perbedaan nilai CINR antara pengukuran dan perhitungan. Beberapa perbandingan ada yang selisihnya kecil dan besar. Perbedaan Nilai CINR ini dapat disebabkan karena kondisi kepadatan rumah dan pepohonan. Dari analisisi di atas dapat disimpulkan bahwa nilai SNR pada WiMAX sangat bergantung pada daerah (terrain) sehingga berpengaruh kepada besarnya RSL. Selain itu, perbedaan ini disebabkan oleh besarnya noise figure untuk menghitung Eb/No dengan asumsi noise figure sebesar $7 \mathrm{~dB}$.

\subsection{Pengukuran Kualitas Layanan}

\subsubsection{Troughput}

Throughput merupakan suatu ukuran yang menyatakan berapa banyak bit sukses yang diterima di tujuan dibandingkan dengan lamanya waktu yang dibutuhkan untuk mengirimkan bit-bit tersebut. Pada kondisi nyata besarnya throughput tergantung dari protokol yang digunakan dalam transmisi (seperti TCP, UDP, dll) dan tipe data yang akan dikirim (FTP, HTTP, SMTP,VoIP, dII). Pengukuran dilakukan dengan menggunakan pengiriman data dari situs youtube yakni berupa data video. Sedangkan untuk melihat angka pengukurannya dilakukan dengan bantuan software net monitor. Berikut hasil pengukuran yang telah dilakukan. 
Tabel 8. Hasil pengukuran Throughput

\begin{tabular}{|c|l|c|c|}
\hline \multirow{2}{*}{ No } & \multirow{2}{*}{ Lokasi Titik Pengujian } & Downlink Troughput (Mbps) \\
\cline { 3 - 4 } & & Average & Max \\
\hline 1 & Gerbang Tol M. Toha & 1 & 1,02 \\
\hline 2 & Tol Padalarang-1 & 0,95 & 1,02 \\
\hline 3 & Tol Padalarang-2 & 0,4 & 0,53 \\
\hline 4 & Tol Padalarang-3 & 0,8 & 1,01 \\
\hline 5 & Tol Padalarang-4 & 0,26 & 0,4 \\
\hline 6 & Dago Pakar & 0,98 & 1 \\
\hline 7 & Manglayang & 0,08 & 0,033 \\
\hline
\end{tabular}

Dari data di atas, nilai terbesar arah downlink terdapat pada titik lokasi gerbang tol M.Toha dengan nilai sebesar $1 \mathrm{Mbps}$ untuk downlink. Hal ini dikarenakan nilai CINR pada CPE ini paling besar diantara CPE lainnya. Jenis modulasi yang digunakan sangat berpengaruh terhadap nilai throughput. Karena semakin tinggi nilai bit per modulasi maka nilai bit rate juga semakin tinggi sehingga nilai throughput juga semakin besar.

\subsubsection{Delay dan Packet Loss}

Delay adalah waktu yang dibutuhkan data untuk menempuh jarak dari titik asal sampai ke titik tujuan. Sedangkan packet loss merupakan banyaknya paket yang gagal mencapai tempat tujuan paket tersebut dikirim. Ketika packet loss besar maka dapat diketahui bahwa jaringan sedang sibuk atau terjadi overload. Packet loss mempengaruhi kinerja jaringan secara langsung. Ketika nilai packet loss suatu jaringan besar, dapat dikatakan kinerja jaringan tersebut kurang baik.

Tabel 9. Hasil Pengukuran Delay dan Packet Loss arah Gateway

\begin{tabular}{|c|l|c|c|c|c|}
\hline \multirow{2}{*}{ No } & \multirow{2}{*}{ Lokasi Titik Pengujian } & \multirow{2}{*}{$\begin{array}{c}\text { Packet } \\
\text { Loss (\%) }\end{array}$} & \multicolumn{3}{|c|}{ Delay (ms) } \\
\cline { 3 - 5 } & & 0 & 57,95 & Average & Max \\
\hline 1 & Gerbang Tol M. Toha & 0 & 62,26 & 81,98 & 98,8 \\
\hline 2 & Tol Padalarang-1 & 0 & 71,37 & 94,70 & 104,02 \\
\hline 3 & Tol Padalarang-2 & 0 & 61,47 & 79,04 & 131,20 \\
\hline 4 & Tol Padalarang-3 & 0 & 85,98 & 139,50 & 187,01 \\
\hline 5 & Tol Padalarang-4 & 0 & 42,87 & 56,15 & 83,82 \\
\hline 6 & Dago Pakar & 20 & 40,46 & 61,11 & 100,38 \\
\hline 7 & Manglayang & & & \\
\hline
\end{tabular}

Dari data diatas, nilai delay terendah didapat pada lokasi Dago Pakar yaitu sebesar 56,247 ms. Sedangkan nilai delay tertinggi didapat pada lokasi Tol Padalarang-2 yaitu sebesar 139,5 ms. Nilai delay dipengaruhi oleh jenis propagasi. Apabila kondisi propagasinya NLOS maka waktu yang dibutuhkan data untuk sampai ke penerima semakin lama karena sinyal dalam pentransmisiannya mengalami pemantulan oleh obstacle. Sedangkan apabila kondisi propagasinya LOS dapat dipastikan sinyal lebih cepat menuju ke penerima karena tidak terjadi pemantulan dan hambatan lainnya. Nilai terbesar untuk packet loss ada di lokasi Manglayang yaitu sebesar $20 \%$. Hal ini dapat disebabkan karena mengingat waktu trafik pada saat pengukuran sedang dalam kondisi sibuk. 


\section{KESI MPULAN}

Berdasarkan hasil penelitian yang telah dilakukan untuk pengujian HiMax 331 SS dapat ditarik sejumlah kesimpulan antara lain:

1) Nilai CINR tertinggi didapat di lokasi Tol Padalarang-1 dengan nilai $31 \mathrm{~dB}$ pada modulasi 64 QAM- 3/4. Sedangkan nilai CINR terendah berada di lokasi Tol Padalarang2 dengan nilai $10 \mathrm{~dB}$ pada modulasi BPSK-1/2. Nilai CINR ditentukan oleh lingkungan propagasi antara BS dan CPE, jika kondisi LOS maka CINR pun makin besar. Berbeda dengan kondisi dimana antara BS dan SS banyak terhalang oleh obstacle seperti pepohonan dan bangunan, nilai CINR yang diperoleh lebih kecil. Jarak juga menentukan besarnya nilai CINR, semakin jauh lokasi SS maka nilai CINR semakin rendah.

2) Nilai RSSI tertinggi didapat $-54 \mathrm{dBm}$ berada di lokasi Tol Padalarang-1 dan nilai RSSI terendah didapat $-89 \mathrm{dBm}$ pada lokasi gerbang Tol Padalarang-2. RSSI dapat disimpulkan sebanding dengan daya pancar dari sumber dan dipengaruhi oleh jarak jangkauan. Jika daya pancar sumber besar, maka nilai RSSI juga besar. Tetapi nilai RSSI berbanding terbalik dengan loss propagasi, semakin besar loss propagasi maka nilai RSSI akan makin kecil. Selain pengaruh dari kondisi propagasi, penyebab besarnya nilai RSSI pada Tol Padalarang-1 karena disebabkan kondisi elevasi yang lebih tinggi.

3) Nilai delay terendah didapat pada lokasi Dago Pakar yaitu sebesar 56,247 ms pada kondisi LOS. Sedangkan nilai delay tertinggi didapat pada lokasi Tol Padalarang-2 yaitu sebesar 139,5 ms pada kondisi NLOS. Pada pengukuran delay, apabila kondisi propagasinya NLOS maka waktu yang dibutuhkan data untuk sampai ke penerima semakin lama. Sedangkan apabila kondisi propagasinya LOS dapat dipastikan sinyal lebih cepat menuju ke penerima karena tidak terjadi pemantulan dan hambatan lainnya.

4) Nilai terbesar untuk packet loss ada di lokasi Manglayang yaitu sebesar $20 \%$. Nilai ini terdapat pada jarak terjauh yaitu 14,3 km di lokasi Manglayang. Hal ini dapat disebabkan karena waktu trafik pada saat pengukuran sedang dalam kondisi sibuk.

5) Nilai throughput tertinggi untuk layanan streaming video pada situs youtube ialah 1 Mbps (downlink) pada modulasi 64 QAM - 3/4. Hal ini dikarenakan nilai CINR pada SS ini paling besar diantara SS lainnya. Jenis modulasi yang digunakan sangat berpengaruh terhadap nilai throughput. Karena semakin tinggi nilai bit per modulasi, maka bit rate nya juga semakin tinggi sehingga throughput-nya juga semakin besar. 


\section{DAFTAR RUJ UKAN}

Noman Shabbir. (2011). Comparison Of Radio Propagation Model For Long Term Evolution (LTE) Network. Pakistan : International Journal od Next-Generation Networks (IJNGN) Vol.3 No.3.

Shahajahan. (2009). Analysis of Propagation Models for WiMAX at 3,5 GHz. Swedia : Master of Science in Electrical Engineering Thesis Blekinge Institute of Technology.

Milanovic, Josip. (2007). Comparison of Propagation Models Accuracy for WiMAX on $3.5 \mathrm{GHz}$. Intitute Electrical and Electronics Engineers.

Ghosh. (2005). Broadband Wireless Access with WiMAX/802.16: Current Performance Benchmarks and Future Potential. IEEE Communications Magazine. 